\title{
REVIEW ON THE DETERMINATION OF TURBULENT FLOW IN CARBONATE AQUIFERS
}

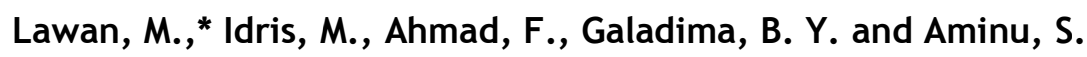 \\ Department of Physics, Bayero University, Kano. \\ ${ }^{*}$ Correspondence Author: mlawal.phy@buk.edu.ng Tel: 08098154974
}

\begin{abstract}
Water is a vital natural resource for people all around the world - whether it is piped to homes or drawn out of wells. Groundwater is vulnerable to pollution. By mapping the way that groundwater flows, we will be able to identify where groundwater may be vulnerable and where to place potential sources of pollution to minimize risk. Turbulent flow mobilize sediment grains and transport them through aquifers, and these suspended sediment impacts water quality. It is important to identify the occurrence of turbulent flow in aquifers and to predict where it is likely to be found. Large apertures, head measurements/spring discharge relationship and rapid velocities are the factors that contribute to the occurrence of turbulent flow in carbonate aquifers and thus this flow is more likely to occur than in other lithologies. The various methods for the determination of turbulent flow are; tracer tests and spring discharge, correlation with spring discharge with heads in well, using map with potentiometric surface trough, areas of large head changes centered on potentiometric surface trough, cave streams and suspended sediment in springs. The probability of turbulent flow increases in a down gradient direction in an aquifer. It also increases as a function of permeability and of spring discharge. Turbulent flow is also a major contributing factor to the occurrence of ground water flooding in carbonate aquifers.

Key words: Turbulent flow, Aquifer, Tracer tests, Spring discharge, Hydraulic conductivity.
\end{abstract}

\section{INTRODUCTION}

The origin of carbonate rock is mainly sedimentary deposits. They consists of limestone, dolomite and marble. Compression, agitation, and dolomitization processes might act on the deposits as they lithify and greatly change their porosity and permeability. However, the principal post depositional change in carbonate rocks is the dissolution of the part of the rock by circulating, slightly acidic groundwater. Solution openings in carbonate rocks range from small tubes and widened joints to caverns that may be tens of meters wide and hundreds to thousands of meters in length. Where they are saturated, carbonate rocks with well-connected networks of solution openings yield large amount of water to wells that penetrate the openings, (water.usgs.gov,2016). The water-yielding properties of carbonate rocks vary widely; some yield almost no water and are considered to be confining units, whereas others are among the most productive aquifers known and are called non confining aquifers. These aquifers supply permanent springs and can be tapped with boreholes to provide water. If the location and characteristics of conduits could be either predicted on theoretical evidence or determined from aquifer measurements then this would offer the possibility of incorporating the conduits into the model and thereby producing a more accurate representation of the aquifer. Tracer testing provides the major evidence for extensive conduits in carbonate aquifers.

Several attempts have been made towards the determination of turbulent flow in carbonate aquifers. Amongst are; "identifying turbulent flow in carbonate aquifers" carried out by, Worthington and Soley (2017). The probability of turbulent flow increases in a down gradient direction in an aquifer and as a function of permeability and of spring discharge. Spring discharge is a key parameter for evaluating the presence of turbulent flow which is likely to occur where a spring with a discharge greater than $1 \mathrm{~L} / \mathrm{s}$ is fed by a single channel.

Another investigation by Coe et al. (2012) explained "the major changes in yield within short distances". Field data results confirm that diffuse, laminar, and turbulent conduit flow are present within the carbonate bedrock aquifer of northwestern Ohio. The hydraulic characteristics of the aquifer are not uniform; there are significant variations in permeability that need to be accounted for within the carbonate bedrock aquifer (i.e. degree of fracturing as well as variation in cementation). 
This helps to explain major changes in yield over short distances in both the vertical and horizontal directions. Overall, because of the degree of interconnectedness of the fractures and conduits in both the vertical and horizontal directions, it must be assumed that the carbonate bedrock aquifer acts as a continuous water bearing unit from the surface to the top of the Rochester Shale at a depth of over 400 feet below the land surface.

Comparison of the discharges obtained at Royal Spring by direct gaging and dye dilution indicate that significant flow is bypassing the spring. This bypassing flow is believed to follow subsurface conduits adjacent to the stream fed from the spring and may be tapped by wells or an interceptor trench. This departure from what is otherwise a simple dendritic flow pattern in the basin probably is due, at least in part, to older downstream spring conduits and outlets being reactivated by the additional head produced by impoundment of the spring. Flow in the groundwater basin feeding the spring is believed to be concentrated in a conduit the position of which is controlled by a major joint and whose gradient is similar to surface streams in the area. The underground stream has a free surface over much of its length and flow is believed to be turbulent. Flow velocities are high, ranging from 0.058 to $0.25 \mathrm{~m} / \mathrm{s}$. "Flow parameters in a shallow conduit-flow carbonate aquifer" by Thrailkill et al (1991).

\section{THEORY}

Whether a flow is laminar or turbulent depends on the relative importance of fluid friction (viscosity) and flow inertia. The ratio of inertial to viscous forces is the Reynolds number. Given the characteristic velocity scale, $\mathrm{U}$, and length scale, $\mathrm{L}$, for a system, the Reynolds number is (basicsofturbulentflowmit.edu); $R_{e}=\frac{U L}{\mu} \quad 1$ where $\mu$ is the kinematic viscosityof the fluid.

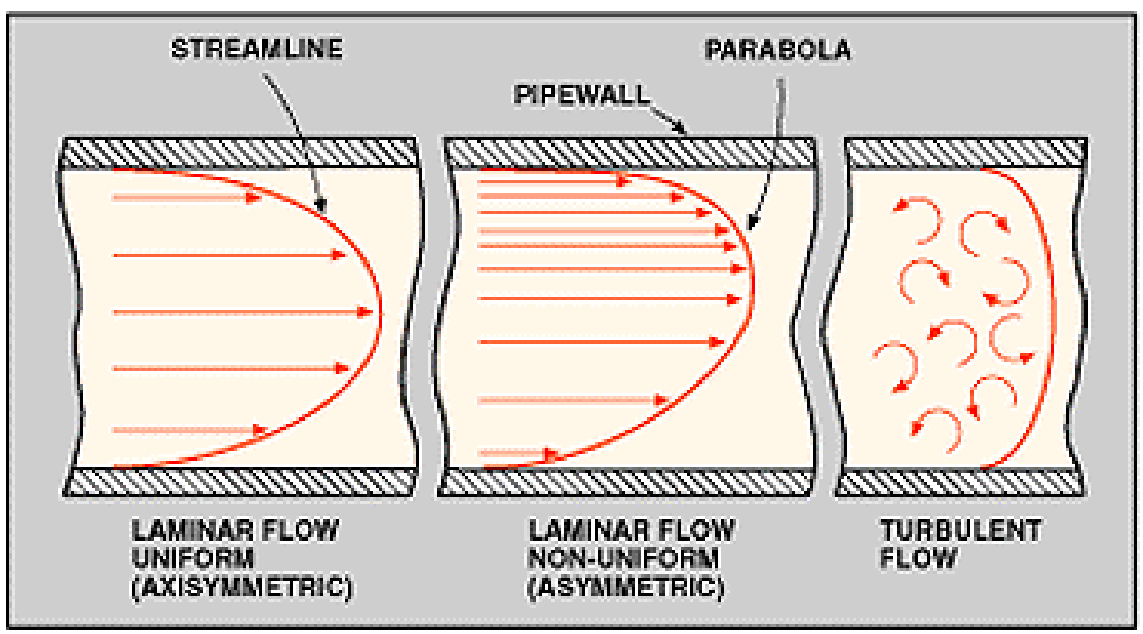

Figure 1: Lamina \& Turbulent Flow ( qph.ec.quoracdn.net).

For most surface water systems the characteristic length scale is the basin-scale. Because this scale is typically large $(1 \mathrm{~m}$ to 100 's km), most surface water systems are turbulent. In contrast, the characteristic length scale for groundwater systems is the pore scale, which is typically quite small $(<1$ $\mathrm{mm}$ ), and groundwater flow is nearly always laminar. The characteristic length-scale for a channel of width $\mathrm{w}$ and depth $\mathrm{h}$ is the hydraulic radius (basicsofturbulentflowmit.edu, 2017), $R_{h}=\frac{w h}{P}$ 2

Where, $\mathrm{P}$ is the wetted perimeter.

For an open channel $P=(2 h+w)$ and for a closed conduit $P=2(h+w)$ (mit.edu).

As a general rule, open channel flow is laminar if the Reynolds number defined by the hydraulic radius(basicsofturbulentflowmit.edu, 2017), $\quad R_{e}=\frac{U R h}{\mu}<500$

As the Reynolds number increases above this limit burst of turbulent appear intermittently in the flow. As $R_{e}$ increases the frequency and duration of the turbulent bursts also increases until $R_{e}>(1000)$, at which point the turbulence is fully persistent. If the conduit boundary is rough, the transition to fully turbulent flow can occur at lower Reynolds numbers. Alternatively, laminar conditions can persist to higher Reynolds numbers if the conduit is smooth and inlet conditions are carefully designed. Groundwater-bearing formations sufficiently permeable to transmit and yield water in usable quantities are called aquifers. 
Most common aquifers are unconsolidated sands and gravels. They are of two types unconfined and confined.

Unconfined aquifers are under-ground lakes in porous materials. Top of the unconfined aquifer is the water table, also called the phreatic surface, after the Greek word phrear, "well". It is the plane where groundwater pressures are equal to the atmospheric pressure. Confined aquifer is a layer of water-bearing material that is sandwiched between two layers of much less pervious material. The pressure condition is characterized by the potentiometric surface, which is the surface obtained by connecting equilibrium water levels in tubes, or piezometers, penetrating the confined aquifer. If the Piezometric Surface is above the upper confining layer, the static water level in a well will be above the aquifer. Such a well is called an artesian well.

The porosity is the percentage that is void of material, it is given by (LAN301M.Fall 2012);

$$
n=\frac{V_{v}}{V} \times 100 \quad 4
$$

Where $V_{v}$ is the void space, $V$ the total volume, and $\mathrm{n}$ porosity.

$$
V_{v}=V-V_{s} \text { and } V_{s}=\frac{m_{s}}{\rho_{s}} \quad 5
$$

The effective porosity is measured by drying the sample at $105^{\circ} \mathrm{C}$ and then submerging it in known volume of water. What goes into the sample is a measure of the effective void space.

Conductivity is the ability of the rock to convey water from one void to another. Hydraulic conductivity is also referred to as the Coefficient of permeability. The Intrinsic permeability is given by(LAN301M. Fall 2012);

$$
\mathrm{K}_{\mathrm{i}}=\mathrm{Cd}^{2} \quad 6
$$

Where $C$ is the shape factor and $d$ is the grain size (diameter)

If two rocks have equal porosity, but different grain size, more water will be retained in the fine grained rock. Specific yield, $S_{y}$ is the ratio of volume of water drained by gravity to total volume while specific retention, $\mathrm{S}_{\mathrm{r}}$ is the ratio of volume of water a rock can retain to total volume. The sum of the specific yield and retention is the porosity, n(LAN301M. Fall 2012)

$$
n=S_{y}+S_{r}
$$

Aquifer transmissivity, is given by(LAN301M.Fall 2012);

$$
T=b K
$$

Where, $T$ is the transmissivity it has the units of $\left[\mathrm{L}^{2} \mathrm{~T}^{-1}\right], \mathrm{b}$ is the thickness of the saturated layer with [L] and $\mathrm{K}$ is called the hydraulic conductivity with $\left[\mathrm{L} \mathrm{T}^{-1}\right]$.

\section{MATERIALS AND METHODS}

Despite different studies such as turbulent flow deduced from bed form-erosional features and sediments in cave passages (Gale,1984), turbulent flow deduced from the combination of tracer velocity and spring discharge (Atkinson, 1977), and also from the combination of head measurements and spring discharge (Bonacci,2001 and Sepulveda,2009) there has been no comprehensive discussion of the range of different methods for determining turbulent flow in aquifers nor of the possibility of turbulent flow occurring in a given carbonate aquifer. The methods that can be used to identify turbulent flow includes among others. The first method calculates Reynold's number from channel diameter and velocity data whereas the other methods uses inductive logic and identify the presence of turbulent flow from water level, spring discharge, groundwater velocity, cave stream, and suspended sediment data. These methods are not extensive. Any methods that yield estimates of channel diameter or groundwater velocity can aid in the determination of turbulent flow.

The first method uses tracer test from a sinking stream to a spring to determine groundwater velocity with a known spring discharge. Continuity equation (Eq. 9) is used to calculate the diameter of the channel from which Reynolds's number (Eq. 10) can also be calculated, i.e. $\quad Q=V A$

9

$$
R=\frac{\rho V d}{\mu}
$$

The second method is by correlating spring discharge with the head differencebetween a well and spring to determine whether the water flow in the channel feeding the spring is laminar or turbulent. Laminar flow is described by Darcy's law. If the flow is turbulent then the head difference is proportional to the square of the discharge (Ford \& William, 2007).

$$
Q=A \sqrt{\frac{2 d g i}{f}}
$$

Where $f=$ Darcy-wasbach friction factor, $g=$ acceleration due to gravity, $\mathrm{i}=$ hydraulic gradient, $\mathrm{A}=$ area and $\mathrm{d}=$ diameter.

Thirdly, the location of major channels are identified from potentiometric surface maps that shows troughs which coincide with major channels. The discharge in the channel is calculated using the expression, (Worthington,2015b)

$$
Q_{C}=I B_{C}
$$

$Q_{C}=$ Discharge at any point along the major channel and $B_{C}=$ Area of ground water basin upgradient from the location and $I$ is the mean infiltration rate 


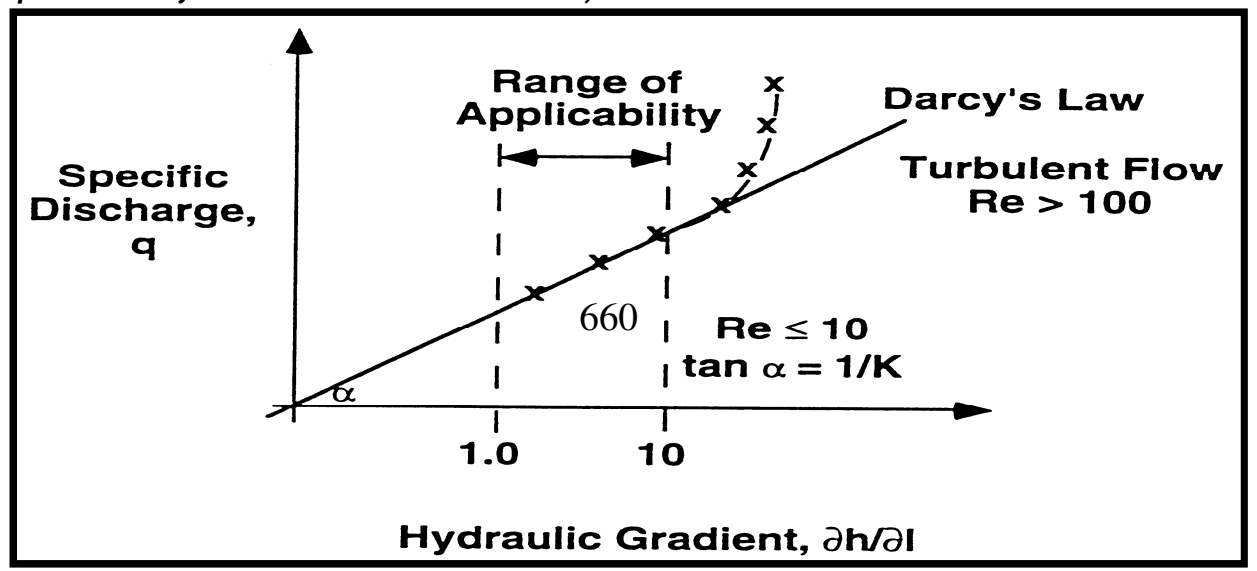

Fig 2: Head as a function of spring discharge.

The Reynolds number is then calculated from the relationship between discharge and the Reynolds's number ( Eq 10).

The fourth method to identify turbulent flow is from the fact that discharge is proportional to the square root of hydraulic gradient. Hence this results in large increase in head in high flow conditions close to channels with turbulent flow.

Mapping of cave streams in which the velocity has been measured is the fifth way to identify turbulent flow. This allows for the Reynolds's number to be determined.

Lastly, the sixth indication of turbulent flow is provided due to the presenceof high turbidity at springs. When velocities exceed $0.2 \mathrm{~m} / \mathrm{s}$ clastic sediments become mobilized in carbonate aquifers.

CONCLUSION

In conclusion there is no comprehensive discussion of the range of different methods for

\section{REFERENCES}

Atkinson, T.C., (1977), Diffuse Flow and Conduit Flow in Limestone Terrain in the Mendip Hills, Somerset (Great Britain), Journal of Hydrology. 35, 93-110.

Bonacci, O., (2001). Analysis of the Maximum Discharge of Karst Spring, Hydrogeology Journal 9, 328-338.

Coe, C.J, C.P.G, P.G and Raab, J.; (2012), Ground Water Investigation of the Carbonate Bedrock Aquifer to Evaluate the Impact of Pumping High-Yielding Irrigation Wells on Local Water Supply Wells in Ottawa County, Harris Township, Ohio Ohio, Department of Natural Resources Division of Soil and Water Resources 2045 Morse Road Columbus Ohio 43229

Ford, D. C and Ford, P.W Williams, (2007); Karst Hydrogeology and Geomophology. Willey, Chichester, England, pp. 562. determining turbulent flow in aquifers nor of the possibility of turbulent flow occurring in a given carbonate aquifer. The first method calculates Reynold's number from channel diameter and velocity data whereas the other methods uses inductive logic and identify the presence of turbulent flow from water level, spring discharge, groundwater velocity, cave stream, and suspended sediment data. These methods are not extensive. Any methods that yield estimates of channel diameter or groundwater velocity can aid in the determination of turbulent flow.

The Reynolds number gives the limit of fluid flow while the spring discharge is the key parameter for evaluating the presence of turbulent flow. The probability of turbulent flow increases in a down gradient direction in an aquifer close to a spring. It also increases as a function of permeability and of spring discharge.

Gale, S.J., (1984), The Hydraulics of Conduit Flow in Carbonate Aquifers, Journal of Hydrology 70, 309-327.

Sepulveda. N., (2009), Analysis of Methods to Estimate Spring Flow in a Karst Aquifer, Ground Water 47, 337-349.

Thrailkill, J.;Sullivan, S.B. and Gouzie, D.R., (1991), Department of Geological Sciences, University of Kentucky, Lexington, KY 40506, USA

Worthington, R.H and Soley, W.N (2017); Determination of turbulent flow in carbonate aquifer, Journal of hydrology, 552(2017)70 80.

www.wikipedia.com, Basics of Turbulent Flow MIT Retrieved on $16^{\text {th }}$ July, 2017.

www.wikipedia.com, /LAN301M. Fall retrieved on $16^{\text {th }}$ July, 2017. 